\title{
Efficacy of Essential Oils from Plant Origin Molluscicides against the Vector Snail Lymnaea acuminata
}

\author{
Farindra Tiwari \\ P. G. Department of Zoology, M. G. P. G. College, Gorakhpur 273 001, Uttar Pradesh, India.
}

\begin{abstract}
How to cite this paper: Farindra Tiwari. (2021) Efficacy of Essential Oils from Plant Origin Molluscicides against the Vector Snail Lymnaea acuminata. International Journal of Food Science and Agriculture, 5(4), 654-657.
\end{abstract}

DOI: $10.26855 /$ ijfsa.2021.12.012

Received: October 19, 2021

Accepted: November 11, 2021

Published: November 17, 2021

*Corresponding author: Farindra Tiwari, P. G. Department of Zoology, M. G. P. G. College, Gorakhpur 273 001, Uttar Pradesh, India.

Email: drfarindra_mgpg@rediffmail.com

\begin{abstract}
Snail control is one of the most important tools in the campaign to reduce the incidence of fascioliasis. Essential oils and/or their constituents are gaining increasing interest for using as safe alternatives to pesticides for controlling various pests including gastropods. In the present study, some of the essential oils demonstrated as potent molluscicides against the vector snail Lymnaea acuminata. The main objective of this research is to evaluate the molluscicidal activity of the essential oils of Cymbopogon nervatus and Boswellia papyrifera against the snail Lymnaea acuminata. It is evident from the present results that $C$. nervatus and $B$. papyrifera essential oils exhibited as strong molluscicides of plant origin. The present study can be helpful to reduce the incidence of fascioliasis. These essential oils may offer an alternative tool for the control of fascioliasis in cattle population of eastern Uttar Pradesh of India.
\end{abstract}

\section{Keywords}

Boswellia papyrifera, Cymbopogon nervatus, essential oils, molluscicidal activity, snail control

\section{Introduction}

Certain freshwater snails are of great economic importance because they act as intermediate hosts for digenean trematodes. Two such flukes, Fasciola hepatica and Fasciola gigantica, are transmitted by the snail Lymnaea acuminata which cause endemic disease fascioliasis in cattle population of eastern region of the state of Uttar Pradesh in India [1-2]. An obvious solution is to reduce the incidence of fascioliasis is to de-link the life cycle of fluke by destroying the vector snails [3-10]. The development of a selective and safe molluscicide should always be a realistic goal. It must be effective at low concentrations and exert minimal adverse effect on the other biota sharing the same habitat with snail. Lack of contact between molluscicides and target snail population due to mushy vegetation, dilution in upwelling sewage water are two main causes of the failure of snail control programme. It has been reported earlier that the utilization of attractants, arrestants, phagostimulants and toxic factors in control release formulations or bait formulations designed to remove trematode host snails from the fresh water environment is cost effective and ecologically acceptable [11]. The snails use chemical signals for locating food sources. These signals are released from the dead and living aquatic organisms into the modular system of the snails [12-16]. Bait formulation containing attractant and a molluscicide is an expedient approach in order to lure the target snail population to the molluscicide. In the present study the essential oils of different plant derived molluscicides have been used against the vector snail Lymnaea acuminata. The interest in essential oils is widespread, and has seen them proven effective against various pests including insects, mites, fungi, and nematodes [17]. The most toxic oils overall seem to be thyme, oregano, basil, rosemary, and mint; however, testing of a wider range of oils on various pests will likely reveal particular activity of certain oils against certain pests [18-25]. 


\section{Materials and Methods}

\subsection{Tested material}

Plant species, Cymbopogon nervatus and Boswellia papyrifera leaves were collected from the botanical garden of the college. These plant materials were carefully examined for identification by the Herbarium at the Botany Department, M. G. P. G. College, Gorakhpur, Uttar Pradesh, India.

\subsection{Isolation of essential oils}

The essential oils of Cymbopogon nervatus leaves and Boswellia papyrifera resin were obtained by hydrodistillation method described in British Pharmacopoeia [26].

\subsection{Collection of Snails}

Adult Lymnaea acuminata $(2.25 \pm 0.20 \mathrm{~cm}$ in length) were collected locally from lakes and low lying submerged fields in Gorakhpur. The snails were acclimatized for 72 hours in dechlorinated tap water at $25 \pm 10 \mathrm{C}$. The $\mathrm{pH}$ of the water was 7.1-7.3 and dissolved oxygen, free carbon dioxide and bicarbonate alkalinity were set to 6.5-7.2 mg/l, 5.2-6.3 $\mathrm{mg} / \mathrm{l}$ and 102.0-105.0 $\mathrm{mg} / \mathrm{l}$, respectively.

Lethal concentration values $\left(\mathrm{LC}_{50}\right)$, lower and upper confidence limits (LCL and UCL), slope values, t- ratio, ' $\mathrm{g}$ ' value and heterogeneity factor were calculated using POLO computer programme [27]. The product moment correlation coefficient was applied between different data obtained in Tables 1 [28].

Table 1. Molluscicidal activity and lethality of Cymbopogon nervatus and Boswellia papyrifera essential oil extracts against the snail Lymnaea acuminata

\begin{tabular}{ccccccccc}
\hline Exposure period & Molluscicides & LC $_{50}$ & LCL & UCL & Slope Value & t-ratio & g-value & Heterogeneity \\
\hline \multirow{2}{*}{$24 \mathrm{~h}$} & Cymbopogon nervatus & 3.57 & 1.07 & 4.38 & $1.8 \pm 0.45$ & 3.92 & 0.24 & 0.28 \\
& Boswellia papyrifera & 2.35 & 0.84 & 4.1 & $1.45 \pm 0.33$ & 4.38 & 0.20 & 0.32 \\
\multirow{2}{*}{$48 \mathrm{~h}$} & Cymbopogon nervatus & 2.99 & 0.93 & 11.29 & $1.12 \pm 0.37$ & 3.03 & 0.41 & 0.15 \\
& Boswellia papyrifera & 2.11 & 0.59 & 2.59 & $1.14 \pm 0.27$ & 4.15 & 0.22 & 0.16 \\
$72 \mathrm{~h}$ & Cymbopogon nervatus & 2.50 & 0.61 & 2.0 & $1.16 \pm 0.34$ & 3.35 & 0.34 & 0.22 \\
& Boswellia papyrifera & 2.70 & 0.24 & 0.45 & $1.34 \pm 0.25$ & 5.21 & 0.14 & 0.28 \\
& Cymbopogon nervatus & 2.1 & 0.64 & 0.88 & $2.61 \pm 0.50$ & 5.22 & 0.14 & 0.29 \\
& Boswellia papyrifera & 1.90 & 0.50 & 0.73 & $2.71 \pm 0.61$ & 4.45 & 0.19 & 0.11 \\
\hline
\end{tabular}

Notes: Product moment correlation showed significant $(\mathrm{p}<0.05)$; negative correlation in between the exposure period and LC $\mathrm{C}_{50}$ of different molluscicides.

\section{Results and Discussion}

Mollusciciding is still considered as the most important means of controlling fascioliasis transmission. In rural communities, the cost of synthetic molluscicides and/or chemotherapy prohibits their use. Plant molluscicides, applied as crude aqueous suspensions are the source of cheap, effective and environmentally acceptable alternatives. The discovery of the potent molluscicidal properties of some plant-derived agents in Mortality was expressed on probit probabilities and plotted against the log. Transformed values of aromatic water extract concentration. The results of the toxicity of the investigated essential water solutions against the tested snails are presented in Table 1.

The slope values given in Tables 1 were steep. Separate estimate of $\mathrm{LC}_{50}$ based on each of the six replicates was found to be within $95 \%$ confidence limits. The t-ratio was greater than 1.96 and the heterogeneity less than 1.0. The ' $\mathrm{g}$ ' value was less than 0.5 at all probability levels $(90,95,99)$.

The essential oil water extracts of the Cymbopogan nervatus leaves exhibited high toxic effects on Lymnaea acuminata (24h LC $\mathrm{L}_{50}$-3.57) whereas the essential oil water solution extract of the Boswellia papyrifera resin also showed high toxic effects (24h $\left.\mathrm{LC}_{50}-2.35\right)$. It was evident from the present results that $C$. nervatus and B. papyrifera essential oils are potential sources of botanical molluscicides. Their toxic effect is dose dependent. This is the first evaluation of these plants against the hosts of fascioliasis. The good results observed offer an alternative tool for the control of fascioliasis. Bioassay-directed fractions of the active crude materials, to isolate and identify the compound responsible of the molluscicidal activity, are essential to understand the mechanisms involved [29-31]. In the conclusion, it can be stated 
that the plant derived essential oils might be used as an effective tool for controlling the molluscan pests to reduce the incidence of fascioliasis. Its further studies can be helpful in integrated snail control programme.

\section{References}

[1] Abd-El Hamid, A. Z. (1997). Development of bait formulation for control of intermediate hosts of African Schistosome species. J. Appl. Toxicol., 17(6): 391-395.

[2] Agarwal, R. A. and Singh, D. K. (1988). Harmful gastropods and their control. Acta Hydrochim Hydrobiol, 16: 113-138.

[3] Chattoraj, A. N. and Tiwari, S. C. (1965). A note on the insecticidal property of Annona squamosa (Annonaceae). Natl Acad Sci India Proc Sec B (Biol Sci), 35: 351-353.

[4] Godan, D. (1983). "Pests slugs and snails. Biology and control” (ed., Dora Godan) translated by Sheila Grouber, Springer Verlog. Berlin, Heidelberg, New York.

[5] Isman, M. B. (2000). Plant essential oils for pest and disease manage-ment. Crop Prot., 19: 603-608.

[6] Isman, M. B. and Machial, C. M. (2006). Pesticides based on plant essential oils: from traditional practice to commercialization. In: Rai M, Carpinella MC (eds.), Naturally occurring bioactive compounds. Elsevier, New York, pp. 29-44.

[7] Klein, M. L., Chastain, T. G., Garbacik, C. J., Qian, Y. P., and Mc Donnell, R. J. (2019). Acute toxicity of essential oils to the pest slug Deroceras reticulatum in laboratory and greenhouse bioassays. J. Pest Sci., 93(1): 1-13.

[8] Kpikpi, J. E. K. and Thomas, J. D. (1992). A study of sugar chemoreception niches of two bulinid snail hosts of schistosomiasis. Ann Trop Med Parasitol, 86: 181-198.

[9] Maclnnis, A. J., Bethal, W. M., and Cornford, E. M. (1974). Identification of chemicals of snail origin that attract Schistosoma mansoni miracidia. Nature, 248: 361-363.

[10] Madsen, H. (1992). A comparative study on the food locating ability of Helisoma duryi, Biomphalaria camerunensis and Bulinus truncatus (Pulmonata: Planorbidae). J Appl Ecol., 29: 70-78.

[11] Marston, A. and Hosttetmann, K. (1985). Plant molluscicides. Phytochemistry, 24: 639-652.

[12] Marston, A. and Hosttetmann, K. (1987). Antifungal, molluscicidal and cytotoxic compounds from plants used in traditional medicines. In: “Biologically Active Natural Products” (Ed. Hosttetmann, K. and Lea, P. J.), Clarendon Press Oxford, pp. 65-83.

[13] Mukerja, T. D. and Govind, R. (1958). Indigenous insecticidal plants: II Annona squamosa. J Indian Res (India), 17C: 9-15.

[14] Ndamba, J. (1995). Response of the molluscicidal berry plant Phytolacca dodecandra to different climatic and edaphic conditions, Trop Agric, 72: 135-140.

[15] Reyes, F. R. and Santos, A. C. (1931). Isolation of Anonaine from Annona squamosa Linn. Philippines J of Sci., 44: $409-410$.

[16] Russel, R. M., Robertson, J. L., and Savin, N. E. (1977). POLO: A new computer programme for probit log analysis. Bull Entomol Soc Amer., 23: 209-213.

[17] Singh, A., Singh, D. K., Mishra, T. N., and Agarwal, R. A. (1996). Molluscicides of plant origin. Biol Agri Hortic., 13: 205-252.

[18] Singh, K., Singh, A., and Singh, D. K. (1996). Molluscicidal activity of neem (Azadirachta indica A. Juss). J of Ethnopharmacol, 52: 35-40.

[19] Singh, K. and Singh, D. K. (2000). Effect of different combinations of MGK-264 and piperonyl butoxide with plant derived molluscicides on snail reproduction. Arch EnvironContam Toxicol, 38: 182-190.

[20] Singh, O. and Agarwal, R. A. (1981). Toxicity of certain pesticides to two economic species of snails in northern India. $J$ Econ Entomol., 74: 568-571.

[21] Sterry, P. R., Thomas, J. D., and Patience, R. L. (1985). Changes in the concentrations of short-chain carboxylic acids and gases during decomposition of the aquatic macrophytes Lemna paucicostata and Ceratophylum demersum. Freshw Biol., 15: 139-153.

[22] Sokal, R. R. and Rohlf, F. J. (1973). Introduction to Biostatistics. W H Freeman, San Francisco, p. 368.

[23] Thomas, J. D. (1982). Chemical ecology of the snail hosts of schistosomiasis: snail-snail and snail- plant interactions. Malacol, 33: 81-91.

[24] Thomas, J. D., Kowalczyk, C., and Somsundaram, B. (1989). The biochemical ecology of Biomphalaria glabrata, a snail host of Schistosoma mansoni; short chain carboxylic and amino acids as phagostimulants. Comp Biochem Physiol, 93A: 899-911.

[25] Tiwari, F. and Singh, D. K. (2004). Behavior responses of the snail Lymnaea acuminata to carbohydrates in snail attractant pellets. Naturewissenschaft en, 91: 378-380.

[26] Tiwari, F. and Singh, D. K. (2004). Attraction to amino acids by Lymnaea acuminata, the snail host of Fasciola species. Braz J 
Med Biol Res., 37: 587-590.

[27] Tiwari, F. (2011). Chemoattractive effect of amino acids against Lymnaea acuminata snails. World Journal of Zoology, 6(2): 117-119.

[28] Tiwari, F. and Singh, D. K. (2007). Toxicity of plant derived molluscicides in attractant food pellets against snail, Lymnaea acuminata. Iranian J of Pharmacol Therapeutics, 6: 103-107.

[29] Tiwari, F. (2013). Behavioural responses of Indoplanorbis exustus snails against different amino acids in bait formulation. Researcher, 5(4): 16-18.

[30] Radwan, M. A. and Gad, A. F. (2021). Essential oils and their components as promising approach for gastropod mollusc control: a review. J. of Plant Diseases and Protection, 128: 923-949.

[31] Blythe, E. K., Tabanca, N., Demirci, B., and Kendra, P. E. (2020). Chemical composition of essential oil from Tetradenia riparia and its attractant activity for mediterranean fruit fly. Ceratitis capitata. Natl. Prod. Commun., 15(9): 1-6. 